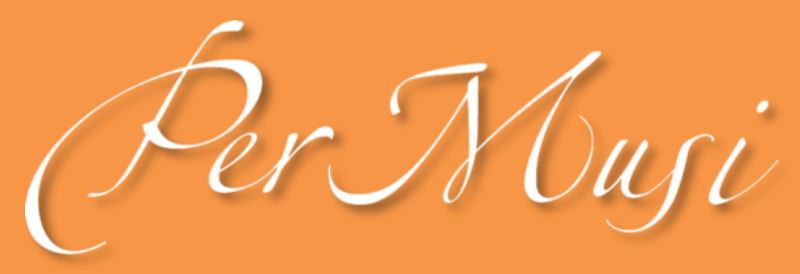

ISSN 2317-6377

\title{
Crítica musical e a significação social de gravações de Prince nos anos 1980
}

\author{
Jonas Soares Lana \\ https://orcid.org/0000-0002-1347-1325 \\ Instituto Federal do Rio de Janeiro, campus Eng. Paulo de Frontin \\ jonas.lana@ifrj.edu.br \\ SCIENTIFIC ARTICLE \\ Submitted date: 30 mar 2020 \\ Final approval date: $11 \mathrm{dec} 2020$
}

Resumo: Este trabalho aborda um debate social iniciado em meados dos anos 1980 por jornalistas e críticos musicais norte-americanos a respeito de dois discos de Prince. O primeiro, Around the World in A Day, foi lançado em 1985; o segundo, Parade: Music from the Motion Picture Under the Cherry Moon, foi lançado em 1986. O debate em torno desses álbuns foi instigado pela suposição de que eles fariam referências a gravações produzidas pelos Beatles em meados dos anos 1960. Este artigo propõe investigar a relação de Prince com jornalistas e críticos musicais, bem como os papéis exercidos por estes e outros agentes sociais no processo coletivo de significação dos álbuns do artista, incluindo músicos que colaboraram na produção deles.

Palavras-chave: Prince e The Beatles; Crítica musical; Significação social da música; Mediação social.

\section{TITLE: MUSIC CRITICISM AND THE SOCIAL CONSTRUCTION OF MEANINGS FOR PRINCE'S MID-1980S RECORDINGS}

Abstract: This work focuses on a social debate raised in the mid-1980s by both American journalists and music critics regarding two of Prince's records. The first, Around the World in A Day, was released in 1985; the second, Parade: Music from the Motion Picture Under The Cherry Moon, was released in 1986. The debate surrounding these records stemmed from assumptions that they referenced albums produced by The Beatles in the late 1960s. This article presents an inquiry on the relationship between Prince, journalists and music critics, as well as on the roles played by these and other social agents in the collective construction of meanings for these Prince's records, including musicians who collaborated in their production.

Keywords: Prince and The Beatles; Music criticism; Music's social meaning; Social mediation. 


\section{Crítica musical e a significação social de gravações de Prince nos anos 1980}

Jonas Soares Lana, Instituto Federal do Rio de Janeiro, jonas.lana@ifrj.edu.br

Entrevistador: Você odeia os críticos de rock? Você acha que eles têm medo de você? Prince: [Risos] Não, isso não tem importância.

Ei, eu tenho medo deles!

Prince, $1985^{1}$

\section{Introdução}

Neste trabalho, abordo um debate estabelecido nos Estados Unidos em 1985 por jornalistas, críticos musicais e Prince (1958-2016), cantor, multi-instrumentista e compositor norte-americano de sucesso em diversas partes do mundo, incluindo o Brasil. O tema desse debate é a "influência" que gravações da banda de rock britânica The Beatles teriam exercido em Prince e que poderia ser reconhecida em dois álbuns que ele gravou com a banda The Revolution, após o sucesso obtido com o disco e o filme intitulados Purple Rain. Refiro-me a Around the World in a Day e a Parade: Music From the Motion Picture Under the Cherry Moon, lançados respectivamente em 1985 e 1986.

O tema surgiu quando eu fazia parte do meu doutorado na Universidade Case Western Reserve, em Cleveland, Estados Unidos. ${ }^{2}$ Eu pesquisava as colaborações de arranjadores norte-americanos na produção fonográfica de canções comercializadas nos Estados Unidos, a fim de compará-las à colaboração de Rogério Duprat como arranjador de canções tropicalistas no final dos anos 1960. Na época, eu ouvia com frequência os discos gravados pelos Beatles no fim da mesma década, buscando compreender os impactos da banda britânica no processo criativo e na produção fonográfica tropicalista. ${ }^{3}$

Cheguei, então, a Parade, LP de Prince com arranjos de Clare Fischer. Em busca de informações sobre o disco, me deparei com a discussão em torno da existência de possíveis referências à obra dos Beatles nele e em Around the World in a Day. Tive contato com o tema ao ler a biografia Prince: inside the music and the masks, escrita por Ronin Ro $(2011,126)$, o qual observa que a polêmica começou quando profissionais da imprensa

\footnotetext{
1 "-Do you hate rock critics? Do you think they're afraid of you? - [Laughs] No, it's no big deal. Hey, I'm afraid of them!". Prince. Entrevista concedida a Neal Karlen 1985, s/p.

2 Os resultados desta pesquisa podem ser acessados em Lana (2013).

${ }^{3}$ Esses impactos foram declarados por diversos integrantes do círculo colaborativo tropicalista. Cf. Campos (1993), Veloso (2008), Mac Cord (2011) e Lana (2013).
} 
sugeriram que o álbum Around the World in a Day incluía elementos sonoros dos discos Sgt. Pepper e de Magical Mystery Tour, ambos gravados pela banda britânica em 1967. Prince, contudo, segundo Ronin Ro, teria negado taxativamente tal sugestão. Instigado por essa rejeição, aprofundei a pesquisa, a qual me permitiu reconstituir tal debate. O tema mobilizou muitos agentes sociais, incluindo jornalistas, críticos musicais e fãs, todos eles em alguma medida engajados em uma disputa pela determinação dos significados das gravações em foco. Iniciada em 1985, essa discussão segue ecoando em livros e publicações congêneres sobre Prince, nos quais Around the World in a Day é o disco mais associado com os Beatles, seguido de Parade.

Neste artigo, introduzo esse debate no contexto mais amplo das relações sempre atribuladas que Prince manteve com a crítica profissional ao longo dos anos 1980 e 1990. Em seguida, analiso a contenda como uma disputa por autoridade. No final do percurso, tomo o debate sobre a presumida "influência" dos Beatles sobre Prince como uma plataforma para discutir a participação de jornalistas e críticos profissionais na construção e difusão de sentidos socialmente atribuídos à obra de Prince e a outros repertórios musicais. Antes, porém, de abordar o debate propriamente dito, proponho uma breve e necessária apresentação do artista e de sua obra, guiado pela produção bibliográfica produzida a respeito.

\section{As controvérsias}

Falecido em 2016, Prince Rogers Nelson e sua obra constituem importantes fenômenos da música popular e da cultura mediatizada norte-americana e mundial. Seu impacto na cultura musical global é comparável ao que foi produzido pelos Beatles, Rolling Stones, Michael Jackson e Madonna. Assim como essas estrelas, Prince lotou estádios esportivos em turnês mundiais. Suas músicas, fonogramas e filmes chegaram diversas vezes ao topo das paradas de vendas de discos e de frequência de veiculação de canções no rádio, como a Billboard. Ao final da vida e de uma carreira de quarenta anos, o artista havia colecionado prêmios como o Grammy Awards e o Oscar, ${ }^{4}$ lançado 39 discos e vendido cerca de cem milhões de cópias (Hawkins 2017).

Esses números confirmam o impacto da produção artística de Prince, que também pode ser medido pela volumosa quantidade de páginas de jornais, revistas, biografias, fóruns de fãs e textos acadêmicos dedicadas a sua vida e obra, particularmente nos Estados Unidos e Reino Unido. No campo da musicologia, Prince é valorizado pela inventividade musical e poética, pelo virtuosismo como cantor e guitarrista e por sua habilidade singular com as técnicas e equipamentos de gravação. Outro assunto frequentemente abordado pelos musicólogos é sua atitude permanente de desafio à ordem patriarcal e à heteronormatividade (Walser 1994; Hawkins 2009; Hawkins, Nieblock 2011; Hawkins 2017). Em muitas de suas letras, videoclipes e shows, Prince construiu uma persona excêntrica e sexualizada, que incorpora características ao mesmo tempo masculinas e femininas, atraindo o interesse de biógrafos ${ }^{5}$ e de pesquisadores de outras áreas, como a de estudos de gênero e sexualidade (Fuchs 1996; Whiteneir 2016; 2019).

Em artigo publicado em 1994, o musicólogo Robert Walser (1994) observou que a ambiguidade de Prince quanto à identidade de gênero seria uma expressão de sua insatisfação com a economia de desejos regulada pelas forças do sistema patriarcal. Walser argumenta que o cantor promovia em suas composições e

\footnotetext{
${ }^{4}$ Prince venceu o Grammy Awards em diversas categorias, e recebeu o Oscar de melhor trilha sonora original para o filme Purple Rain em 1985.

${ }^{5}$ Cf. Ro (2011), Touré (2014), Thorne (2016) e Greenman (2017).
} 
performances o deslocamento constante de signos empregados para afirmar a distinção binária, central para a organização social dos conceitos de gênero, orientação sexual e, no caso norte-americano, de raça. Esses deslocamentos simbólicos se tornaram fontes de muitas controvérsias, as quais possuem centralidade na carreira de Prince. Muitas dessas polêmicas foram instigadas por performances e canções com teor sexual explícito, a exemplo de Darling Nikki, cuja letra descreve uma cena de masturbação. Distribuída aos milhões no disco Purple Rain em 1984, a faixa suscitou uma campanha exitosa para o controle do acesso a conteúdos considerados inapropriados para crianças e adolescentes. ${ }^{6}$

As polêmicas em torno de Prince não se limitaram, contudo, a questões de gênero e sexualidade; envolvia também, entre outros assuntos, a suposta "influência" dos Beatles nos discos Around the World in a Day e Parade. A repercussão dessa polêmica pode ser medida por sua presença em diferentes fontes de pesquisa, incluindo longas discussões no fórum do fã-clube oficial do artista (www.prince.org) e livros ensaísticos e biográficos (Ro 2011, Touré 2014; Thorne 2016; Greenman 2017; Vogel 2018).

Algumas dessas fontes citam a entrevista concedida por Prince para a revista Rolling Stone em 1985 como marco inicial do debate sobre esse tema. ${ }^{7} \mathrm{Na}$ ocasião, o jornalista Neal Karlen (1985) perguntou ao artista se ele se incomodava com as pessoas dizendo que ele estaria "voltando no tempo" com o então recém-lançado Around the World in a Day. Em resposta, Prince foi taxativo: "Não. O que dizem é que os Beatles são a influência. A influência não foram os Beatles" [grifos do autor]. ${ }^{8}$

Prince estaria fazendo uma possível referência a uma crítica de Robert Palmer a Around the World in a Day, publicada no New York Times seis meses antes. Em seu artigo, Palmer observa que o disco seria fortemente ligado ao rock dos anos 1960, seja pela arte da capa, seja pelos temas das letras e sonoridades:

De fato, o novo disco de Prince talvez devesse ter sido intitulado Around Great 60's Rock in a Day. Ele evoca o rock dos anos 1960, ou pelo menos os mitos do rock dos anos 1960, em muitos sentidos, da arte de sua capa, que lembra o aspecto de desenho animado de Yellow Submarine dos Beatles, às letras, estilos musicais e vocais. ${ }^{9}$

No mesmo texto, o crítico não poupa Prince, sugerindo que o álbum talvez traduzisse uma demanda do artista para ser levado a sério. Palmer afirma em seguida que "se 'Sgt. Pepper' dos Beatles é um dos álbuns

\footnotetext{
${ }^{6} \mathrm{O}$ movimento se institucionalizou com a formação de um comitê chamado Parents Music Resource Center. Em 1996, uma década mais tarde, o comitê conseguiu aprovar a obrigatoriedade de inserção de um selo nas capas de discos com conteúdo classificado como impróprio para crianças e adolescentes. O selo trazia o seguinte texto: "Parental Advisory - Explicit Content" (Hawkins 2017).

${ }^{7}$ A entrevista foi concedida em setembro de 1985, seis meses após o início da gravação de Parade, conforme o website oficial do músico. Esse disco seria lançado em 1986 (informações obtidas em The Prince Estate Official Website).

8 "-Does it bother you when people say you're going back in time with Around the World in a Day?

- No. What they say is that the Beatles are the influence. The influence wasn't the Beatles" [grifos do autor] (Karlen 1985, s/p).

9 "In fact, Prince's new album might more accurately have been titled Around Great 60's Rock in a Day. It is redolent of 60's rock, or at least of 60's rock myths, in many ways, from the cover art, which recalls the Beatles' Yellow Submarine cartoon feature, to the lyrics, the musical stylings and the vocals." (Palmer 1985, seção C, 16).
} 
de rock mais universalmente reverenciados como uma obra de arte, Prince claramente gostaria que Around the World in a Day fosse o $\mathrm{n}$ - 2, pelo menos". ${ }^{10} \mathrm{E}$ prossegue com outras associações:

De fato, um primeiro informe de fontes da indústria fonográfica de que o álbum seria o Sgt. Pepper de Prince foi substancialmente preciso. Foi depois de terem feito Sgt. Pepper e percebido que jamais seriam capazes de tocar uma música com tamanha riqueza e complexidade no palco que os Beatles concordaram formalmente em jamais tocá-lo ao vivo novamente. Muito da música de Around the World in a Day enfrentaria problemas similares, e o álbum já estava concluído e pronto para o lançamento quando Prince anunciou que estava desistindo de apresentações ao vivo. ${ }^{11}$

\section{A "influência"}

Para o aparente desgosto de Prince, o tema da "influência" dos Beatles perseguiu o artista ao longo de toda a sua carreira (Thorne, 2016). Alguns dos principais estudiosos de sua vida e obra reafirmaram a existência de conexões entre sua obra e a dos britânicos. Touré (2014) é categórico: no álbum Around the World in a Day, o artista "convoca a era psicodélica dos Beatles, especialmente Sgt. Pepper's Lonely Hearts Club Band". ${ }^{12}$ Com a mesma segurança, e a formação adicional em musicologia, Stam Hawkins (2017) considera que "o efeito da banda de Liverpool em Prince foi profundo e discernível em canções como Raspberry Beret, presente em Around the World in a Day". Esse efeito também foi reconhecido em críticas profissionais ao disco Parade em 1986 (Vogel 2018). Hawkins acredita que o vínculo entre o artista norte-americano e os britânicos tenha sido confirmado anos mais tarde: "a profunda admiração de Prince pelos Beatles foi posteriormente corroborada por seu legendário solo de guitarra de dois minutos em While My Guittar Gently Weeps" em performance ocorrida em 2004. ${ }^{13}$

10 "He is also asking, perhaps demanding, to be taken seriously. If the Beatles Sgt. Pepper is the one rock album almost universally revered as a work of art, Prince clearly would like Around the World in a Day to be No. 2, at least." (Idem).

11 "In fact, an early report from record-business sources that the album would be 'Prince's Sgt. Pepper was substantially accurate. It was after making Sgt. Pepper and realizing they would never be able to play music of such richness and complexity on stage that the Beatles formally agreed never to perform live again. Much of the music on Around the World in a Day would be likely to pose similar problems, and the album was already completed and ready for release when Prince announced that he was giving up live performance." (Idem).

12 "He summons the psychedelic era of the Beatles, especially Sgt. Pepper's Lonely Hearts Club Band" (Touré 2014, s/p).

13 "The Beatles' effect on Prince was profound and discernible in songs such as "Raspberry beret." Prince's deep admiration for this Liverpool band was further borne out by his legendary two-minute guitar solo in "While my guitar gently weeps," the performance by Tom Petty, Steve Winwood, Jeff Lynne, and others in tribute to George Harrison upon Harrison's induction into the Rock and Roll Hall of Fame in 2004" (Hawkins 2017, 125). Composta por George Harrison, a canção While My Guitar Gently Weeps foi gravada pelos Beatles em The Beatles, conhecido como "Álbum Branco" (1968). 
Toda essa história começou, ao que tudo indica, com o artigo do crítico Robert Palmer, que não usou, no entanto, a palavra "influência" em seu texto. Foi Prince quem a empregou na entrevista a Neal Karlen.

Nos dicionários Cambridge e Merriam-Webster de língua inglesa, as definições para "influence" são muito semelhantes àquelas encontradas no Dicionário Houaiss de Língua Portuguesa. Em síntese, os dois primeiros definem "influência" como o poder ou capacidade de causar um efeito por meios indiretos ou intangíveis, sem o aparente exercício de força ou comando. ${ }^{14}$

Na declaração de Prince a Karlen, a acepção de "influência" tem caráter social. O artista opera a palavra referindo-se a efeitos exercidos por certos agentes sobre sua subjetividade e processo criativo. Sob a lente das teorias antropológicas e sociológicas de Alfred Gell (1998) e Bruno Latour (2005), a palavra pode ser compreendida como um conjunto de agenciamentos exercidos pelos Beatles e por suas gravações, ou, segundo os autores citados, respectivamente, por "pessoas"/"humanos" e "objetos"/"não humanos". ${ }^{15}$ Nos termos de Antoine Hennion (1993; 2003) esses agentes são "mediações sociais" produtoras de efeitos e de consequências como uma ideia musical, composição, gravação, referência a outras criações musicais, e assim por diante. Esses autores notam que essas forças são múltiplas, assim como são múltiplos os agentes sociais e os efeitos que os primeiros geram uns nos outros. Isso significa que uma subjetividade e seu processo criativo não são consequência do agenciamento único de uma banda ou de um repertório, como os Beatles e suas gravações, mas de um conjunto numeroso e heterogêneo de músicos, composições, gravações, muitos dos quais exerceram "influência" sobre Prince sem que ele tivesse consciência disso. Afinal, dirão esses cientistas sociais, o exercício da força agentiva e suas consequências tendem a passar desapercebidos, porque naturalizados no processo de socialização.

Causação de efeitos intangíveis, a "influência" é característica de qualquer prática musical, aqui entendida como um processo social criativo que envolve algum nível de seleção/reaproveitamento ou rejeição de materiais sonoros gerados em experiências sociomusicais pregressas. ${ }^{16}$ Uma das dificuldades para observála é que os agenciamentos, além de múltiplos quanto às origens e destinos das forças exercidas, podem se manifestar de modo constante e reiterado, mas também prolongado e esparso. Veja-se o caso de Prince, e de sua forte relação com a música negra norte-americana. $\mathrm{O}$ artista teve contato com esse universo musical desde a infância, o que, como um conjunto de composições e gravações, contribuiu para a formação do seu gosto e de um repertório pessoal de ideias e procedimentos composicionais e interpretativos. Essa formação se deu ao longo de anos, de maneira lenta e imperceptível, assim como acontece com o aprendizado da língua nativa. Em ambos os casos, naturalizamos a nossa relação com um repertório linguístico ou musical, tendendo a ignorar o caráter sociocultural desse processo.

Tudo isso dificulta a observação dos efeitos causados por uma "influência" enquanto ela acontece. Restanos, nesse sentido, buscar nas gravações de Prince os elementos poéticos e sonoros que possam ter sido identificados como oriundos de gravações dos Beatles e, portanto, como resultados desse agenciamento.

14 Cf. Influence. Cambridge Dictionary; Influence. Merriam-Webster Dictionary; Influência. Dicionário Houaiss de Língua Portuguesa (2001).

15 Os "objetos" são agentes quando operam em uma rede de relações sociais.

16 Este é um pressuposto teórico estruturante das abordagens da música em campos como as ciências sociais, etnomusicologia e parte da musicologia histórica. Para uma reflexão recente sobre tal premissa, $C f$. Barros (2016). 


\section{Os discos}

O álbum Around the World in a Day foi lançado em 1985, após o impacto de Purple Rain, LP com a trilha sonora para o filme homônimo, estrelado por Prince em 1984. Assim como o filme, o disco Purple Rain obteve grande sucesso comercial, atingindo o primeiro lugar nas paradas de sucesso. Nesse álbum, Prince manteve um estilo híbrido que vinha amadurecendo em sua carreira e que se consolidou no disco anterior, lançado com o título 1999. Em linhas gerais, esse estilo se baseava em construções melódicas, harmônicas e rítmicas que remetiam aos universos do rock e do funk. Tais construções foram realizadas com bateria eletrônica, sintetizadores e a guitarra virtuosa com a qual Prince remetia ao repertório de Jimmy Hendrix e Santana.

Em Around the World in a Day, Prince manteve algumas dessas características estilísticas, mas não se limitou a elas. O artista foi além, introduzindo elementos como arranjos para cordas, padrões rítmicos e instrumentos da música tradicional árabe. A busca por sonoridades não ocidentais é associada nesse álbum a letras mais introspectivas e espiritualizadas, o que levou críticos a relacionarem o disco ao rock psicodélico dos anos 1960 - e para alguns, como Robert Palmer, à fase psicodélica dos Beatles. Matt Thorne (2016) afirma que Around the World in a Day representa o marco inicial de um processo de ampliação do repertório mobilizado no processo criativo de Prince que também marcaria Parade. Com esse movimento, argumenta Thorne, o artista evitou se tornar refém do estilo que o consagrou no disco Purple Rain. Como ocorre na carreira de outros músicos populares, a aposta de Prince na experimentação implicou a redução do sucesso comercial. Nos Estados Unidos, foram vendidos dois milhões de cópias de Around the World in a Day, em contraste com os treze milhões de Purple Rain. A recepção pela crítica, por sua vez, foi relativamente melhor. Parte dela, no entanto, desagradou a Prince ao insinuar que o disco trazia alusões a produções fonográficas dos Beatles. Que alusões seriam essas? A escuta pautada por esse debate nos permite reconhecer possíveis referências que se distribuem esparsamente nas letras e arranjos de algumas faixas.

A letra de Paisley Park ${ }^{17}$ descreve um parque que abriga e protege seus frequentadores das angústias causadas pelas regras que regulam a vida cotidiana. Na canção Around the World in a Day, ${ }^{18}$ a letra convida o ouvinte a viajar para o interior da mente. Em ambos os casos, Prince exprime o desejo de evasão, seja pela ânsia de transposição para um espaço utópico, seja pela promoção de estados alterados de consciência. Ambos os temas estão presentes na obra dos Beatles, mas também em diversos discos de rock produzidos no final dos anos 1960, por artistas vinculados ao movimento hippie e a outras vertentes da contracultura.

As referências aos Beatles podem ter sido encontradas em faixas de Around the World in a Day que trazem timbres até então inéditos na discografia de Prince e exóticos para os padrões da música pop da época. $\mathrm{Na}$ faixa que dá nome ao álbum, a viagem para o interior da mente leva também para fora, rumo a uma paisagem sonora que se pode chamar genericamente de árabe. Ela é sugerida por um arranjo com textura rítmica e melódica feita com sons acústicos e sintetizados de instrumentos típicos de conjuntos de música tradicionais praticadas no território que se estende do norte do continente africano até a Turquia, incluindo o alaúde, flauta ney, darbuka e címbalos. Em Paisley Park um sintetizador produz um timbre (em 0:11 da gravação)

17 Prince 1985. Paisley Park. Prince; The Revolution [compositores]. In: Prince, Lado A, Faixa 2. Apresento a referência de cada gravação apenas na primeira vez em que ela aparece no texto, a fim de não me tornar repetitivo.

18 Prince 1985. Around the World in a Day. Prince; Nelson, John L.; Coleman, David. [compositores]. In: Prince, Lado A, Faixa 1. 
que evoca o calíope e o órgão a vapor presentes em Being for the Benefit of Mr. Kite, gravada pelos Beatles no disco Sgt. Pepper. Essa sonoridade é obtida com a modulação da amplitude (chamada também de efeito tremolo), a qual foi extensamente aplicada na produção fonográfica dos britânicos. Outro recurso empregado na gravação de Prince, ainda em Paisley Park, é a duplicação da voz de Prince no final de cada estrofe, sobre a cadência VI - VII - I (em 01:01 e outros momentos da gravação). Esses dois elementos remetem, respectivamente, a experimentações de alteração de vozes nos discos dos Beatles e à passagem harmônica que conecta as faixas Sgt. Pepper's Lonely Hearts Club Band ${ }^{19}$ e With the Little Help From My Friends ${ }^{20}$ no disco Sgt. Pepper. Finalmente, vale mencionar a inserção de sons "não musicais" em Pop Life (algo que parece ser parte de uma luta de boxe, em 3:02 da gravação), a exemplo do que fazem os Beatles no referido disco.

Se em Around the World in a Day Prince arrisca aproximações com culturas musicais fora dos padrões ocidentais, em Parade o artista privilegia os arranjos orquestrais, universo pouco explorado em seus discos anteriores. Gravado com a banda The Revolution e lançado em 1986, Parade traz a colaboração do arranjador Clare Fischer, que na época já havia composto arranjos para Os Jacksons (Torne 2016), Dizzy Gillespe e Herbie Hancock (Vogel 2018). Seguindo o caminho de Purple Rain, Parade foi lançado como trilha sonora de um novo filme estrelado por Prince, intitulado Under the Cherry Moon. Em termos comerciais, ambos passaram longe do sucesso comercial do disco e filme Purple Rain. O álbum Parade vendeu um milhão de cópias nos Estados Unidos, em contraste aos treze milhões do disco Purple Rain. Under the Cherry Moon, por sua vez, teve bilheteria de dez milhões de dólares, valor muito inferior aos cerca de setenta milhões arrecadados com o filme Purple Rain. Under the Cherry Moon também não teve êxito com a crítica especializada (Greenman 2017). Parade, pelo contrário, recebeu crítica favorável, por consequência da aposta renovada de Prince na experimentação (Vogel 2018). Para Thorne (2014), Parade seria o disco mais ousado de Prince, pelo modo como conciliou as sonoridades orquestrais com uma seção rítmica que prezou pela economia de meios. Nessa combinação, alguns críticos teriam reconhecido mais uma vez a "influência" dos Beatles.

Em Parade, os críticos podem ter encontrado referências aos Beatles nas quatro primeiras faixas das sete que repartem o lado A do LP. São elas: Christopher Tracy's Parade, ${ }^{21}$ New Position, ${ }^{22}$ I Wonder $U,{ }^{23}$ e Under the Cherry Moon. ${ }^{24} \mathrm{~A}$ primeira faixa descreve uma parada ou desfile de rua, que é protagonizada por Christopher Tracy. Em 0:30 da gravação, Prince canta que "o show continuará, a menos que chova limonada de morangos [strawberries]", o que para alguns poderia ser uma alusão à letra psicodélica da canção Strawberry Fields Forever, dos Beatles (1967). ${ }^{25} \mathrm{Na}$ letra de Prince, Christopher Tracy circula pelas ruas tocando piano sobre um carro. O piano não aparece, contudo, no arranjo, em que soam flautas transversais, trompetes, cordas, flautas sintetizadas e a seção rítmica, formada por baixo elétrico e bateria (em 0:08 e 0:54 da gravação). As flautas e trompetes, em particular, introduzem motivos musicais frequentes em

19 The Beatles 1967a Sgt. Pepper's Lonely Heart Club Band (reprise). Lennon, John; McCartney, Paul [compositores]. In: The Beatles, Lado B, faixa 5.

${ }^{20}$ The Beatles 1967a. With the Little Help From My Friends. Lennon, John; McCartney, Paul [compositores]. In: The beatles, Lado A, faixa 2.

${ }^{21}$ Prince 1986a. Christopher Tracy's Parade. Prince; Nelson, John L. [compositores]. In: Prince, Lado A, Faixa 1.

22 Prince 1986a. New Position. Prince [compositor]. In: Prince, Lado A, Faixa 2.

${ }^{23}$ Prince. I Wonder U. Prince [compositor]. In: Prince, Lado A, Faixa 3.

24 Prince 1986a. Under the Cherry Moon. Prince [compositor]. In: Prince, Lado A, Faixa 4.

25 The Beatles 1967. Strawberry Fields Forever. Lennon, John; McCartney, Paul [compositores]. In: The Beatles, Lado B, faixa 2. 
composições para bandas marciais, algo que também ocorre na canção Sgt. Pepper's Lonely Hearts Club Band.

Em Parade, no final da faixa Christopher Tracy's Parade, ouvimos o que parece ser o som de rodas de trem batendo sobre os trilhos. Novamente, são sons considerados "não musicais", os quais retornam na forma de risos de plateia em I Wonder $U$, terceira faixa do disco (em 05:00 da gravação). No entanto, vale ressaltar que a adição de sons ditos "não musicais" em gravações de canções pode ter sido emprestada a Prince por incontáveis discos de rock e outros gêneros de música popular gravados desde o final dos anos 1960 até a época de gravação de Around the World in a Day e de Parade, em meados dos anos 1980. Alguém poderia reivindicar que os risos de plateia, em particular, seriam alusões aos Beatles, visto que estão presentes na faixa Sgt. Pepper. No entanto, esse argumento perde força quando consideramos que se trata de uma presença relativamente isolada.

Outros três procedimentos que aparecem em pontos esparsos das primeiras quatro faixas de Around the World in a Day podem ter sido entendidos como alusões à obra dos Beatles. O primeiro é a construção de transições musicais entre as faixas que substituem o silêncio que costuma separá-las nos discos de música popular. O segundo consiste em duas evocações sonoras de uma imagem estereotipada do oriente que podem ser relacionadas às referências que gravações dos Beatles fazem à música indiana. Em Parade, esses fragmentos são o som de gongo, em Under the Cherry Moon (em 0:00 e 2:03), e frases executadas em quartas por um par de flautas sintetizadas, em Christopher Tracy's Parade (em 0:01), as quais reproduzem uma pseudomúsica tradicional chinesa, como tocada em filmes de artes marciais. Uma última referência aos Beatles pode ter sido reconhecida no glissando ascendente que encerra I Wonder $U$. No final da faixa (em 1:26), cordas executam esse gesto até a culminância em um acorde dominante (Si Maior), seguido de um acorde prolongado de tônica (Mi Maior). Algo de análogo ocorre na última faixa de Sgt. Pepper, intitulada $A$ Day in the Life, em que um longo glissando culmina em um acorde de tônica (Mi Maior) que dura 45 segundos. ${ }^{26}$

\section{Os músicos}

Os elementos sonoros e poéticos passíveis de associação com a obra dos Beatles, conforme indicados anteriormente, não me parecem suficientemente numerosos e concretos para sustentar afirmações sobre a "influência" da banda no processo de criação de Around the World in a Day e de Parade. A dificuldade de se assegurar a existência de alusões aos Beatles nos discos de Prince pode decorrer da maneira como ele concebia suas composições e gravações, como notado pela musicóloga Anne Danielsen. Em seu estudo sobre o álbum Diamond and Pearls, lançado por Prince em 1991, Danielsen (1997) observa que as faixas desse disco estão repletas de elementos provenientes de repertórios de outros compositores, intérpretes ou gêneros musicais específicos. Se por um lado, a musicóloga mostra segurança ao afirmar a existência de tais empréstimos, por outro, ela não esconde o limite que os procedimentos composicionais de Prince impõem

${ }^{26}$ The Beatles 1967a. A Day in the Life. Lennon, John; McCartney, Paul [compositores]. In: The Beatles Lado B, faixa 6. Composto por George Martin, esse glissando é percebido como tal, mas concretamente consiste em uma combinação de movimentos cromáticos assíncronos com predominância ascendente, que são produzidos por quarenta instrumentos de orquestra, distribuídos nas seções de cordas, madeiras, metais e percussão (MacDonald 2007). O glissando de I Wonder, diferentemente, ascende apenas nas cordas, de modo suave e relativamente convencional. 
a qualquer tentativa de localizar as fontes de onde ele retirou tais materiais. Isso porque, para a autora, o artista não trabalhava com a "citação", prática que é reconhecida como tal apenas quando o material emprestado é identificado como uma referência nítida à criação ou estilo previamente elaborado por outrem. Em Diamond and Pearls, as referências são múltiplas, fragmentadas e integradas em uma textura que inviabiliza a tarefa de isolá-las e reconhecê-las como citações. Algo semelhante ocorre em Around the World in a Day e em Parade. Como no disco analisado por Danielsen, as referências aos Beatles nos discos em foco não são incontestes, porque muito fragmentadas.

Essa fragmentação acentua a dificuldade de se reconhecer em Prince as mencionadas referências à obra dos Beatles. Como dito anteriormente, uma "influência" é o efeito que um ou mais agentes sociais exercem sobre outrem de modo imperceptível e prolongado. Cada elemento que localizei nos dois discos de Prince pode ser um mesmo efeito produzido por diferentes agentes. Afinal, procedimentos composicionais e fonográficos atribuídos a uma banda ou artista, como os Beatles, também foram praticados por outras bandas e artistas, visando inclusive a adequação às exigências de estandardização desenvolvidos pela indústria fonográfica ao longo de sua história.

Essa percepção é reforçada por Lisa Coleman, pianista e tecladista da banda The Revolution na época da gravação desses discos. Em entrevista a Matt Thorne (2016), Lisa observa que Prince gravou Around the World in a Day após ser impactado pelo contato com músicas tradicionais do mundo árabe.

Não eram aos Beatles a quem nós estávamos nos referindo, era provavelmente às mesmas coisas às quais os Beatles estavam se referindo. Nós estávamos procurando o que eles procuraram. [...] Meu irmão tocava world music, ele tocava alaúde, violoncelo, címbalos e darbuka. Quando Prince conheceu esses caras, ele ficou realmente baqueado e impressionado. Foi na nossa cena que o Prince se ligou. ${ }^{27}$

Para a musicista, Prince não se referia, portanto, ao conteúdo dos discos dos Beatles, mas às relações que estabeleceram com tradições musicais não ocidentais, bem como aos procedimentos empregados pelos britânicos no sentido de combinar elementos sonoros e poéticos relacionados ao rock e a esses repertórios tradicionais.

Contudo, a perspectiva de Coleman contraria a visão de outros dois colegas da banda The Revolution no período de gravação de Around the World in a Day e Parade. Matt "Dr." Fink e Bobby Z, músicos que tocavam, respectivamente, teclado e bateria, relataram em 2016 que durante uma viagem de ônibus da turnê de Prince na época da gravação de Around the World in a Day, os três teriam ouvido Good morning, Good Morning, faixa do disco Sgt. Pepper. Bobby Z afirmou que naquele momento Prince

entendeu que os Beatles eram mais do que ele pensava. Ele de certo modo os engoliu. Você pode dizer que Around the World in a Day - estou presumindo muito, e ele provavelmente ficaria enlouquecido com isso - mas estou presumindo que, por ter engolido Magical

27 "It wasn't The Beatles we were referencing, it was probably the same things The Beatles were referencing. We were seeking what they sought [...]. My brother was a world musician, he played the oud and cello and finger cymbals, darbuka hand drum. When Prince met those guys he was really blown away and impressed. It was our scene that we had going that Prince tuned into." Lisa Coleman, citado por Thorne (2016, s/p). 
Mystery Tour e Sgt. Pepper, Around the World in a Day é definitivamente influenciado por eles. $^{28}$

Nesse sentido, Fink e $Z$ engrossam o coro de jornalistas e críticos profissionais, para quem os discos de Prince de 1985 e 1986 trazem elementos que demonstram a "influência" dos Beatles sobre o artista norteamericano, coro esse que, como vimos acima, cresceu progressivamente ao longo dos anos com a entrada de novas vozes, algumas delas situadas no campo da musicologia, como Stan Hawkins, especialista em Prince. Em consideração à autoridade científica dessas vozes, insistirei brevemente nessa tese.

Se a versão sobre a "influência" dos Beatles em Prince está correta, devemos então refletir sobre a rejeição taxativa pelo artista à tal presunção. Diante do "não" de Prince, devemos supor que a conexão efetiva com os discos dos Beatles teria passado despercebida por ele? Ou que o cantor teria sido vítima de escolhas de integrantes da Revolution ou do arranjador Clare Fischer?

Isso parece factível quando consideramos a liberdade de criação que Prince dava a Fischer, conforme relato do próprio arranjador, em entrevista concedida em 2008: "[Prince] me envia o que ele gravou, e eu adiciono a minha orquestra. Ele ocasionalmente me dá alguma sugestão no início do projeto, mas na maioria das vezes me deixa decidir". ${ }^{29}$ Anos mais tarde, essa narrativa foi fortalecida pelo filho Brent Fischer, que trabalhou com o pai na produção dos arranjos para Parade. Em entrevista a Thorne (2016), Brent relembra que Prince se ausentou das sessões de gravação dos arranjos de orquestra para Parade. Depois disso, Prince ligou para Clare, elogiou os arranjos e disse que sua qualidade o convencia de que o melhor seria ficar longe do estúdio para não tolher a liberdade criativa do arranjador.

Alguns dos principais estudos sobre Prince descrevem os membros da banda The Revolution, por sua vez, como colaboradores ativos na composição e gravação dos arranjos para os discos lançados pelo artista no início dos anos 1980, incluindo Around the World in a Day e Parade. Conversas com algumas das pessoas mais próximas de Prince, incluindo Matt "Dr." Fink e Wendy Melvoin da Revolution, convenceram Matt Thorne (2016) de que qualquer abordagem crítica da obra de Prince deveria considerar a colaboração dos integrantes das bandas com quem ele se apresentava e gravava. Segundo Ben Greenman (2017), a tecladista Lisa Coleman e a guitarrista Wendy Melvoin foram as principais parceiras de Prince na composição e arranjo de algumas das canções registradas por ele durante o período em que trabalhava com a Revolution, entre 1984 e 1986. Em Around the World in a Day, elas colaboraram na composição de America e na criação do arranjo para violas em Raspberry Beret. Parade inclui outras duas participações da dupla, na composição de Mountains e Sometimes it Snows in April. Após a dissolução da banda, Lisa afirmou à imprensa que ela e Wendy "embelezaram a visão musical de Prince". ${ }^{30}$

28 "That moment, I think he realized that the Beatles were more than he thought. He just kind of swallowed them up. You can tell that Around the World in a Day - I'm just assuming a lot, and he'd probably get mad but I'm assuming that by swallowing up Magical Mystery Tour and Sgt. Pepper tat Around the World in a Day is definitely influenced by it". Bobby Z, em entrevista concedida a Zaleski (2017).

29 "[Prince] sends me what he has recorded, and I add on my orchestra. He may occasionally give me a suggestion of some kind at the beginning of a project, but mostly leaves it up to me." (Clare Fischer em entrevista a Seymour Nurse 2008).

30 "We embellished his musical vision". Lisa Coleman, citado por Greenman (2017, s/p). 
Se nesse clima colaborativo, Clare Fischer e os integrantes da Revolution encontraram oportunidades para inserir referências aos Beatles nos discos de Prince, contrariando a sua vontade, temos que lidar com duas situações hipotéticas. Na primeira, Prince seria alienado do processo de produção de seus próprios discos. Esse cenário é bastante improvável, se considerarmos que algumas das supostas referências aos Beatles em Parade não foram deixadas pela orquestra de Fischer. O sampling dos risos da plateia, a continuidade entre as faixas e a música de artes marciais tocada em sintetizadores podem ter sido concebidos pelo próprio Prince. Além de experiente tecladista, Prince era um cantor e compositor de canções reconhecidamente provido de "um controle singular sobre o processo de gravação e arranjo", o qual, para Hawkins e Nieblock $(2011,130)$, não teria precedentes no universo da música popular mediatizada. Então, fica difícil conceber que as referências aos Beatles nas faixas dos discos de Prince sejam fruto de um acidente, de uma mera coincidência. A não ser que Prince desconhecesse parcial ou totalmente as gravações dos Beatles a ponto de ser incapaz de reconhecê-las, pressuposto minado pelo relato de Matt "Dr." Fink e Bobby Z sobre o momento em que ouviram com Prince uma faixa do disco Sgt. Pepper.

A segunda hipótese é que tal "influência" teria surgido depois de Prince ouvir os Beatles. O testemunho sobre Prince ouvindo os britânicos no ônibus constitui evidência concreta, mas o mesmo não pode ser dito sobre a presunção de Bobby $Z$ - e dos referidos musicólogos - a respeito das consequências desse contato. Como vimos anteriormente, se há referências a gravações dos Beatles em Around the World in a Day e Parade, elas são ambíguas e questionáveis. O que é inequívoco nesse caso, é que Bobby $\mathrm{Z}$ foi instigado por um jornalista a especular sobre o assunto. A rigor, ele foi estimulado pelo próprio debate sobre a "influência" dos Beatles sobre Prince. E por isso mesmo essa presunção torna-se relevante neste trabalho, na medida em que pode ser entendida como um efeito da publicação de ideias defendidas por profissionais da imprensa e seus textos, essas "pessoas" e "objetos" que, inseridos em uma rede de relações sociais, colaboram na construção coletiva dos significados socialmente atribuídos à música.

\section{A autoridade}

Prince sempre se mostrou reativo e beligerante quando questionado sobre a "influência" de Beatles em seus discos. Essa atitude, contudo, não se restringiu apenas ao período em que promovia os discos Around the World in a Day e Parade. Em entrevistas concedidas antes e depois desse período, o artista também costumava reagir mal a perguntas dos entrevistadores. Essas reações eram frequentes quando as perguntas envolviam interpretações sobre sua obra, mas também ocorriam após questionamentos relacionados a outros temas, como vemos no trecho escolhido como epígrafe deste trabalho. Nessa passagem, como em muitas outras, Prince é evasivo e ambíguo. Ele responde, mas não diz nada. Isso vale inclusive para o "não" à "influência" dos Beatles, que a rigor não esclarece a questão formulada pelo jornalista sobre o artista estar voltando no tempo em Around the World in a Day. Paradoxalmente, a postura evasiva e ambígua de Prince produziu resultados eficazes: ele deixava questões em aberto, sem, com isso, inviabilizar a entrevista que seria publicada para promover seus discos e shows. Quando dizia sem responder, de modo sistemático e reincidente, Prince acabava por questionar, ainda que indiretamente, a legitimidade das perguntas e de quem as formulava. Nesse contexto, o "não" à "influência" dos Beatles pode ser entendido menos como uma fala verdadeira ou falsa, e mais como uma afirmação de poder em uma disputa por autoridade e pelo controle dos sentidos atribuídos a sua produção musical.

Dez Dickerson, músico que acompanhou Prince no início da carreira, observa que a atitude ambígua e evasiva de Prince seria uma tática contra o sensacionalismo da imprensa. "Se eles não iriam imprimir o que de fato 
ele disse", interroga Dickerson, "por que simplesmente não inventar coisas? Eu não acredito que exista qualquer malícia nisso [...], era apenas um modo sagaz de responder ao que ele percebia como desonestidade da imprensa." ${ }^{31}$ Essa observação foi feita em entrevista concedida a Matt Thorne, autor que descreve Prince e os profissionais da imprensa em uma relação de permanente conflito. Segundo Thorne, Prince já mostrava sua indisposição com os críticos em 1982, quando gravou a sardônica All the Critics Love $U$ in New York. Desde então, observa, o artista reafirmou sua desconsideração por quem escrevia sobre sua música, em declarações como "nada que um crítico possa me dizer servirá para o meu aprendizado", publicada em nova entrevista para a Rolling Stone em 1990. ${ }^{32}$

Na entrevista de 1985, em que Prince rejeita a "influência" dos Beatles em Around the World in a Day, o jornalista começa com uma pergunta sobre o que teria levado Prince a se afastar da imprensa por um longo período - o título da matéria na Rolling Stone é "Prince: o silêncio foi quebrado". Em resposta, ele questiona os textos de críticos profissionais a discos recentes de Stevie Wonder e Miles Davis. Em seguida, destaca a avaliação positiva dada por George Clinton a seu disco, acentuando sua importância no universo do funk norte-americano. Prince afirma a seguir que as palavras de Clinton significavam muito mais do que as de "mamma-jammas ${ }^{33}$ de óculos e camisa de crocodilos atrás de uma máquina de escrever." ${ }^{34} \mathrm{Na}$ entrevista de 1990, Prince diz que só respeita o que músicos dizem sobre sua obra (citada por Thorne 2016, 7). Nesse sentido, Prince busca alicerçar sua autoridade no lugar de fala de músico, embora não dizendo isso explicitamente. O músico que ocupa esse lugar é especificamente negro, se considerarmos os exemplos que Prince oferece: Wonder, Davis e Clinton. Os mamma-jammas, por seu turno, são brancos: Neal Karlen, jornalista que o entrevistou para Rolling Stone em 1985 e 1990, autores de biografias e congêneres, como Ronin Ro e o autodeclarado mamma-jamma Matt Thorne, os musicólogos Robert Walser, Stan Hawkins e Anne Danielsen, além dos integrantes da banda The Beatles e de mim, o autor deste texto. $O$ incômodo causado em Prince por jornalistas e críticos musicais pode, portanto, ter um fundo racial, assunto que afeta o artista, conforme sinaliza em muitas de suas canções (Perry 2019) e que em alguma medida pode fundamentar a rejeição por Prince à "influência" dos músicos britânicos.

Prince manifesta-se de maneira reativa, buscando deslegitimar as falas dos críticos e jornalistas. Não devemos, no entanto, assumir que ele não se interessasse por afirmar os sentidos de sua obra, como se estivesse permanentemente desprovido de engajamento para fazer-se entender. Ele queria ser entendido sim, mas apenas através de sua produção poética, musical, cênica e imagética, julgando a explicação verbal

31 "If they weren't going to print what he actually said, why not just make things up? I don't believe there was any malice in this, but it was just a precocious way of responding to what he felt was the press' dishonesty" (Throne 2016, 8).

32 "He was done with critics as early as 1982, when he recorded the sardonic 'All the critics love $u$ in New York', and he never misses an opportunity to remind the lowly writer that he has little regard for anyone who spends the majority of their time at a desk. [...] in a 1990 Rolling Stone interview with Neal Karlen, Prince maintained, 'There's nothing a critic can tell me that I can learn from"' (Thorne 2016, 6-7).

${ }_{33}$ Mamma-jamma é forma modificada de mammy-jammer, um eufemismo para motherfucker, termo de sentido pejorativo genérico, como "filho da puta" ou "sacana". Sou grato ao tradutor Paulo Henriques Britto por essa informação.

34 "Not long ago I talked to George Clinton, a man who knows and has done so much for funk. George told me how much he liked Around the World in a Day. You know how much more his words mean than those from some mamma-jamma wearing glasses and an alligator shirt behind a typewriter" (Prince. Entrevista concedida a Neal Karlen 1985). 
um meio inadequado para realizar essa comunicação. Sua obra deveria ser ela mesma o meio privilegiado para comunicar ao público os sentidos de seus próprios conteúdos e formas.

A esse respeito, Alan di Perna observou em 1994 que Prince "aparenta cultivar uma profunda desconfiança sobre o mundo escrito ou falado". ${ }^{35}$ Essa observação foi publicada um ano após Prince ter substituído o

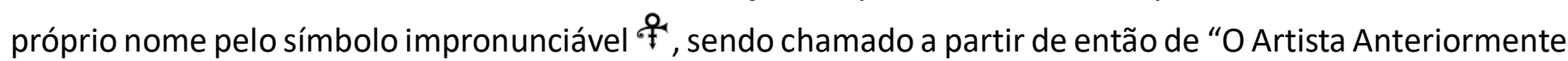
Conhecido como Prince" ou como "O Artista". Ainda em 1994, o musicólogo Robert Walser interpretou essa mudança como parte de um movimento que o "Artista" teria realizado para enfraquecer o domínio da gravadora Warner sobre os direitos autorais incidentes sobre a sua obra. Walser reconheceu o gesto como um ato coerente com os esforços que Prince empreendeu ao longo da carreira para frustrar "a pretensão da linguagem à universalidade". ${ }^{36}$ Desde os anos 1980, observa Walser, Prince vinha utilizando o próprio corpo como plataforma para questionar, na prática, a suposta neutralidade da linguagem, como o fizeram, em termos teóricos, Deleuze e Guattari no livro $O$ anti-Édipo. Segundo Walser, Prince performava uma persona queer, em desafio aos efeitos normativos e coercitivos do sistema binário patriarcal. Em alguns momentos, o artista questionava sua própria identidade racial. Tudo isso era expresso, segundo Walser, em fluxos, fusões e delírios, elementos que compõem a linguagem do desejo. A imagem ambígua de Prince e a adoção do símbolo como nome impronunciável constituiriam, para Walser, uma espécie de denúncia e um desafio aos efeitos normativos da linguagem verbal, entendida como recurso para classificação e controle das diferentes identidades, formas de vida, ontologias. Prince questionava, em outras palavras, a autoridade da linguagem verbal, como instância capaz de fornecer e estabilizar sentidos para a poesia, a música e os movimentos do corpo na performance.

As observações de Walser nos ajudam a compreender que Prince não questiona apenas a sugestão de "influência" dos Beatles sobre sua criação, mas a própria legitimidade de jornalistas, críticos e, em sentido mais amplo, a legitimidade da própria linguagem verbal para representar a realidade - linguagem de que dispõem esses profissionais para descrever a música e mediar a relação do púbico com o artista e sua obra. Entre a explicação verbal e a expressão poética, musical e coreográfica, Prince opta pela segunda, aproximando-se, assim, de outros músicos da diáspora africana, para os quais a música tem sido uma fonte corporificada e subjetiva de contestação de concepções colonizantes que privilegiam a linguagem como forma dominante de consciência humana (Gilroy 2001, 160). E quando colocado frente a frente com um repórter, em uma relação fundamentalmente mediada pela palavra, Prince adota a ambiguidade como uma espécie de instrumento de resistência.

\section{A crítica como mediação social (considerações finais)}

A resistência de Prince à sugestão sobre a "influência" dos Beatles e sua reiterada desautorização de jornalistas e críticos têm, portanto, um fundamento político. Presumo que essa deslegitimação tenha produzido consequências reais, como a indução de parte de seu público a rejeitar ou ignorar o que esses profissionais escreviam sobre seus discos e shows. Ao fazer isso, o artista buscava reduzir a propagação da ideia de que havia algo dos Beatles em Around the World in a Day e em Parade. Desse modo, Prince intervinha como um agente capaz de alterar o modo como as pessoas escutam e dão sentido às suas músicas. O mesmo pode ser dito sobre os críticos profissionais e suas críticas. Assim como Prince, esses escritores e

35 "The man seems to harbor a deep mistrust of the written or spoken word." Alan di Perna $(1994,54)$.

36 "Prince's name foils the pretensions of language to universality" (Walser 1994, 87). 
seus escritos são, nos termos do sociólogo Antoine Hennion (1993; 2003), "mediações sociais" que participam no processo coletivo de significação de sua música. Como dissemos anteriormente, essas "mediações" são agentes que interferem nesse processo, abrangendo "pessoas", como Prince, Clare Fischer, integrantes das bandas The Revolution e The Beatles, os jornalistas e críticos profissionais, mas também, conforme Hennion, "objetos", como sons, palavras, publicações, discos, escuta etc. Essas e outras "mediações" elaboram coletivamente uma compreensão social da produção musical de Prince.

Nesse sentido, ainda que não se possa comprovar a "influência" concreta dos Beatles sobre a produção desses registros, podemos dizer que ainda assim ela existe, uma vez que é percebida por ouvintes influenciados pela crítica profissional. Jornalistas, críticos e suas críticas medeiam a relação do público com o artista e sua produção artística, participando ativamente no processo social de significação da música. Eles são fundamentais para que as alusões aos Beatles se tornem "realidade", sendo percebidas por ouvintes que de outro modo permaneceriam alheios a elas. Os críticos realizam uma espécie de serviço público de decifração, de escavação arqueológica em busca de fragmentos que possam ser reunidos, dando novo sentido às canções. Cumprindo essa atribuição profissional, não raro prazerosa, eles traduzem músicas com palavras que alimentam a curiosidade e levam fãs distraídos a darem replay no disco para confirmar em novas descobertas.

Os resultados desta pesquisa encaminham para uma última discussão sobre a relação entre críticos musicais e pesquisadores acadêmicos. De um ponto de vista sociológico, os conteúdos apresentados em congressos, artigos e livros desempenham, ainda que com alcance muito menor, um papel similar ao das críticas musicais veiculadas em jornais, revistas e, mais recentemente, em websites e redes sociais. Como os jornalistas e críticos profissionais, os acadêmicos traduzem os múltiplos sentidos da música - em grande medida apreendidos por processos e técnicas corporais, não intelectivos (López Cano 2006; Clayton, Dueck e Leante 2013, Lana 2018) -, com base em análises do texto musical e do contexto histórico, social e cultural em que ele é produzido. Por isso mesmo, os acadêmicos tendem a travar com os profissionais da imprensa uma disputa pela legitimidade de seus discursos e pela hegemonia no processo social de significação da música.

Como disse no início deste trabalho, o que me levou a empreender uma análise de gravações de Prince foi minha busca por experiências de diálogo criativo entre compositores, cantores e arranjadores, a exemplo do que ocorria com os Beatles e George Martin na Inglaterra e, no Brasil, com os cantores e compositores tropicalistas e Rogério Duprat, o qual foi o tema da minha pesquisa de doutorado (Lana 2013). Devo confessar que, no estágio inicial da pesquisa de doutorado, eu nutria grande resistência às interpretações sobre o tropicalismo musical pelo crítico Nelson Motta (2000), talvez por sua onipresença na mídia, recontando sua experiência em primeira mão junto aos tropicalistas. Nesse primeiro momento, eu lia as narrativas de Motta como fontes parciais e mistificadoras do tropicalismo musical. Essa leitura mudou quando, ainda no doutorado, examinei as críticas de Augusto de Campos (1993) às gravações tropicalistas de Caetano Veloso e Gilberto Gil. Em um primeiro momento, essas críticas me interessaram pelo uso preciso que Campos fazia de categorias analíticas empregadas por musicólogos e críticos literários. Não tardou, no entanto, para que eu entendesse que essas mesmas categorias serviam para legitimar a música tropicalista como manifestação estética distinta e superior. Ao concluir a tese, eu havia entendido que Campos e Motta, cada um à sua maneira, colaboraram para disseminar interpretações sobre o cancioneiro tropicalista, as quais acabaram por conferir a esse repertório sentidos que hoje são tomados como se the fossem inerentes. Tais sentidos, em boa medida, mistificam, sim, as composições, personas e performances tropicalistas, mas que nem por 
isso se tornam irrelevantes para o pesquisador interessado no modo como as "mediações sociais" contribuem no processo social de significação da música.

O mesmo pode ser dito sobre os críticos musicais que contrariam Prince com as suposições sobre a "influência" dos Beatles. Em boa medida, eles inventaram o diálogo do artista com a banda britânica dos Beatles em Around the World in a Day e em Parade. A análise musical que esbocei neste artigo indica que esses críticos se basearam em fundamentos empíricos muito frágeis, talvez movidos por uma beatlemania que encontra a banda e sua música Here, There and Everywhere. Talvez esse diálogo não passe de fabulação, de fantasia. Mas a música - e a poesia das letras, em menor intensidade - é um terreno polissêmico e por isso mesmo fértil à imaginação. Com a ajuda dos jornalistas e críticos musicais, a fiç̧ão de Beatles em Prince firmou raízes nesse terreno, tornando-se realidade na tessitura simbólica da cultura.

\section{Referências}

\subsection{Referências bibliográficas}

Barros, Frederico. 2016. "Sociologia da música: entre o rigor historicista e a crítica da arte". In Música e ciências sociais: Para Além do Descompasso Entre a Arte e a Ciência. Editado por Dimitri C. Fernandes e Carlos Sandroni, 31-58. Curitiba: Editora Prismas.

Campos, Augusto de (Ed.). 1993. Balanço da bossa e outras bossas. São Paulo: Editora Perspectiva.

Clayton, Martin, Dueck, Byron, and Leante, Laura. 2013. "Introduction: Experience and Meaning in Music Performance". In Experience and Meaning in Music Performance, ed. Martin Clayton, Dueck Byron and Laura Leante, 1-16. Nova York: Oxford University Press. Kindle edition.

Danielsen, Anne. 1997. "His name was Prince: a study of diamonds and pearls". Popular Music 16 (3): $275-$ 291. doi: $10.1017 / \mathrm{S} 0261143000008412$

Di Perna, Alan. 1994. "The guitarrist formerly known as Prince". Guitar world. Nov: 50-64; 196.

Fuchs, Cynthia J. 1996. "I wanna be your fantasy': Sex, death, and the artist formerly known as Prince". Women \& Performance: A Journal of Feminist Theory 8(2): 137-151. doi: 10.1080/07407709608571235

Gell, Alfred. 1998. Art and agency: an anthropological theory. Oxford: Clarendon Press.

Gilroy, Paul. 2001. Atlântico negro: modernidade e dupla consciência. Rio de Janeiro: Editora 34.

Greenman, Ben. 2017. Dig if you will the picture: funk, sex, god, and genius in the music of Prince. Nova York: Henry Holt.

Hawkins, Stan. 2009. "Chelsea Rodgers' was a model: vocality in Prince of the twenty-first century". In The Ashgate Research Companion to Popular Musicology, ed. D. Scott, 335-48. Burlington, VT: Ashgate.

Hawkins, Stan. 2017. "The sun, the moon and stars: Prince Rogers Nelson, 1958-2016". Popular Music and Society, 40(1): 124-128. doi: 10.1080/03007766.2016.1245482.

Hawkins, Stan, and Niblock, Sarah. 2011. Prince: the making of the pop phenomenon. Farnham (England); Burlington (USA): Ashgate.

Hennion, Antoine. 1993. L'histoire de l'art: leçons sur la médiation. Réseaux, 11(60), 9-38. Disponível em: https://www.persee.fr/doc/reso_0751-7971_1993_num_11_60_2365. 
Hennion, Antoine. 2003. "Music and mediation: toward a new sociology of music". In The Cultural Study of Music: a critical introduction, ed. M. Clayton, T. Herbert and R. Middleton, 80-91. Nova York: Routledge.

Lana, Jonas Soares. 2013. Rogério Duprat, arranjos de canção e a sonoplastia tropicalista. Rio de Janeiro: Programa e Pós-Graduação em Ciências Sociais da Pontifícia Universidade Católica do Rio De Janeiro. (Tese De Doutorado).

Lana, Jonas Soares. 2018. "Sobre o programa de escuta musical tropicalista: fonografia, agência e alteridade". El Oido Pensante, 6(1): 7-31. Disponível em: http://ppct.caicyt.gov.ar/index.php/oidopensante. Acesso em 30 jan 2020.

Latour, Bruno. 2005. Reassembling the social: an introduction to actor-network-theory. Nova York: Oxford University Press.

López Cano, Rubén. 2006. "What Kind of Affordances are Musical Affordances? A Semiotic Approach". L'ascolto Musicale: Condotte, Pratiche, Grammatiche. Terzo Simposio Internazionale Sulle Scienze del Linguaggio Musicale.

Mac Cord, Getúlio. 2011. Tropicália: um caldeirão cultural. Rio de Janeiro: Ed. Ferreira.

MacDonald, Ian. 2007. Revolution in the head: the Beatles' records and the sixties. Chicago: Chicago Review Press.

McDonald, Kari, and Kaufman, Sarah Hudson. 2002. "Tomorrow never knows': the contribution of George Martin and his production team to the Beatles' new sound". In Every sound there is: The Beatles' Revolver and the transformation of rock and roll, edited by R. Russell, 139-157. Abingdon, Reino Unido: Routledge.

Motta, Nelson. 2000. Noites tropicais: solos, improvisos e memórias musicais. Rio de Janeiro: Ed. Objetiva.

Perry, Twila L. 2019. "Prince: double-consciousness in expressing the value of work". Howard Journal of Communications, 30(2): 202-210. doi: 10.1080/10646175.2018.1539678.

Ro, Ronin. 2011. Prince: inside the music and the masks. New York: St. Martin's Press.

Thorne, Matt. 2016. Prince: the man and his music. Chicago: Bolden; Agate.

Touré. 2013. I would die 4 u: why Prince became an icon. Nova lorque: Atria Books.

Veloso, Caetano. 2008. Verdade Tropical. São Paulo: Companhia de Bolso.

Vogel, Joseph. 2018. This thing called life: Prince, race, sex, religion, and music. London; Oxford: Bloomsbury.

Walser, Robert. 1994. "Prince as queer poststructuralist". Popular Music \& Society, 18(2): 79-89. doi: $10.1080 / 03007769408591556$

Whiteneir Jr, Kevin. 2019. "Dig if you will the picture: Prince's subversion of hegemonic black masculinity, and the fallacy of racial transcendence". Howard Journal of Communications, 30(2): 129-143. doi: 10.1080/10646175.2018.1536566

Whiteneir Jr, Kevin. 2016. "The purple Prince: how Prince subverted gender through costume, performance, and eroticism". Dress, 42(2): 75-88. doi: 10.1080/03612112.2016.1215804

\subsection{Referências discográficas}

Prince, Around the World in a Day, Paisley Park/Warner. 1985. 
Prince, Parade - Music From the Motion Picture Under the Cherry Moon, Paisley Park/Warner. 1986.

The Beatles. Magical Mystery Tour. Parlophone/Capitol. 1967b.

The Beatles. Sgt. Pepper Lonely Hearts Club Band. Parlophone/Capitol. 1967a.

\subsection{Outras fontes}

Fischer, Clare. 2008. The bottom end. [Entrevista concedida a] Seymour Nurse. Londres (Inglaterra). Disponível em: https://www.thebottomend.co.uk/Clare Fischer artists.php. Acesso em 15 out 2019.

Grammy Awards. 2019. Prince (artist). Disponível em: https://www.grammy.com/grammys/artists/prince/5675. Acesso em 15 out 2019.

Influence. In: Cambridge Dictionary. Disponível em: https://dictionary.cambridge.org/pt/dicionario/ingles/influence. Acesso em: 27 jan. 2020.

Influence. In: Merriam-Webster Dictionary. Disponível em: https://www.merriam-webster.com/dictionary/influence. Acesso em: 27 jan. 2020.

Influência. In: Dicionário Houaiss da Língua Portuguesa. São Paulo: Editora, 2001. 1 CD-ROM.

Karlen, Neal. 1985. Prince talks: the silence is broken. Rolling Stone, São Francisco (Califórnia, EUA), 12 set. Disponível em: https://www.rollingstone.com/music/music-news/prince-talks-the-silence-is-broken58812. Acesso em: 27 jan 2020.

Oscar. 2019. The 57th Academy Awards (1985). Disponível em: https://www.oscars.org/oscars/ceremonies/1985. Acesso em 15 out 2019.

Palmer, Robert. 1985. Records: Prince's "Around the world". The New York Times, Nova York, 22 abr, sessão C, p. 16. Disponível em: https://www.nytimes.com/1985/04/22/arts/records-prince-s-around-theworld.html. Acesso em 30 jan 2020.

Prince.Org - Online Fan Community. Disponível em: www.prince.org. Acesso em 30 jan 2020.

The Prince Estate - Official Website. Discography. Disponível em: https://discography.prince.com/albums/parade. Acesso em $17 \mathrm{dez} 2019$.

Under the cherry moon. 1986. Direção de Prince. EUA: Warner Bros (100 min.).

Zaleski, Annie. 2017. When Prince heard The Beatles' "Sgt. Pepper's Lonely Hearts Club Band" for the first time: exclusive interview. Difuser, Greenwich, Connecticut: 26 mai. Disponível em: https://diffuser.fm/prince-sgt-pepper/. Acesso em 3 jan 2020. 